\title{
Snapshot observation of the physical structure and stratification in deep-water of the South Caspian Sea (western part)
}

\author{
P. Ghaffari ${ }^{1,2}$, H. A. Lahijani ${ }^{3}$, and J. Azizpour ${ }^{2}$ \\ ${ }^{1}$ Department of Geosciences, University of Oslo, Blindern, 0315, Oslo, Norway \\ ${ }^{2}$ Deptartment of Physical Oceanography, Iranian National Center for Oceanography, No. 3, Western Fatemi, \\ 1411813389, Tehran, Iran \\ ${ }^{3}$ Deptartment of Geology, Iranian National Center for Oceanography, No. 3, Western Fatemi, 1411813389, Tehran, Iran
}

Received: 6 October 2009 - Published in Ocean Sci. Discuss.: 10 November 2009

Revised: 3 August 2010 - Accepted: 20 September 2010 - Published: 7 October 2010

\begin{abstract}
The physical parameters structures and different water masses using CTD measurements in southwestern part of the Caspian Sea (CS) adjacent to Anzali Port (AP) are investigated. CTD profiles were conducted along a transect perpendicular to the coastline on 13 stations from the coast down to $720 \mathrm{~m}$ on 22 January 2008 . According to the results the continental shelf waters are located in the surface mixed layer. The surface mixed layer extends itself down to almost $100 \mathrm{~m}$ in outer areas of the continental shelf with a weak seasonal thermocline layer between 80 to $140 \mathrm{~m}$ Freshwaters inflow of local rivers is clearly seen outside the continental shelf at the surface layers. Investigating the dissolved oxygen reveals that winter convection is traceable down to $500 \mathrm{~m}$ in the lateral waters over the shelf break. Among the deeper stations that are located in continental rise and abyssal plain, $300 \mathrm{~m}$ seems to be a threshold for penetration of seasonal changes; therefore deeper waters tend to be impermeable against seasonal variances. Despite the small variations, stability is positive in the study area and temperature plays an important role in static stability and in triggering the lateral mixing. In view of both temperature-salinity and temperature-oxygen distributions in the southwestern part of the CS, two different water masses are separable in cold phase. Snapshot observations of physical properties in the early winter 2008 , to some extent revealed that a mixing was triggered at least in the lateral waters of the study area.
\end{abstract}

Correspondence to: P. Ghaffari (peygham.ghaffari@geo.uio.no)

\section{Introduction}

The Caspian Sea (CS) is the world's largest lake in both area and volume that lies in among Iran, Azerbaijan, Russia, Kazakhstan, and Turkmenistan (Safarov et al., 2008; Zaker et al., 2007). In addition to the northern shallow basin, the CS consists of two deep basins in south and central parts which are separated by a sill. Almost $60 \%$ of the total water mass of the CS is located in deep water (below $200 \mathrm{~m}$ ) and it can be classified as a deep inland sea based on its peculiarities of the thermohaline structure and water circulation (Lebedev and Kostianoy, 2006; Peeters et al., 2000) .

The main inflow comes from the Volga River, which discharges into the northern basin, contributing about $80 \%$ of the total water inflow while freshwater input from the Iranian side is extremely limited (Rodionov, 1994). The northern part of the CS plays an important role in the water circulation among the whole basin. Every cold phase the surface ice sheets covers this part and forms dense water which sinks down toward the central basin, consequently the central basin dense water flows to the southern part. Obviously the dense water formation in the northern basin is depending on the freshwater discharge. Higher freshwater budget means low dense water formation and consequently causes hampering of mixing process. Another well-known scenario for mixing in the CS is winter convection. Usually winter cooling triggers mixing over the water column in most parts of the CS. Moreover cold and dense water tongues are formed by cold shallow water of the lagoons and rivers in the lateral boundary of the basin (Terziev et al., 1992). Unfortunately this water body still is very poorly known in terms of instrumental observation particularly in the southern part along the Iranian

Published by Copernicus Publications on behalf of the European Geosciences Union. 
Table 1. Statistics of meteor-parameters prior and after to field survey from 16-27 January 2008 (I. R. of Meteorological Org, 2008).

\begin{tabular}{crrrccl}
\hline $\begin{array}{c}\text { Day } \\
\text { Jan } 2008\end{array}$ & $\begin{array}{c}\text { Air Temp } \\
(\max )\end{array}$ & $\begin{array}{c}\text { Air Temp } \\
(\mathrm{min})\end{array}$ & $\begin{array}{c}\text { Precipitation } \\
(\mathrm{cm})\end{array}$ & $\begin{array}{c}\text { Wind Speed } \\
(\max )\end{array}$ & $\begin{array}{c}\text { Wind Direction } \\
(\text { degree })\end{array}$ & $\begin{array}{c}\text { Weather } \\
\text { Condition }\end{array}$ \\
\hline 16 & 1.6 & -1.6 & 69.7 & 17 & 340 & Snow \\
17 & -1.0 & -2.0 & 26.2 & 06 & 270 & Snow \\
18 & 2.6 & -6.8 & 0.9 & 10 & 330 & Snow \\
19 & 2.2 & -4.0 & 0.8 & 11 & 310 & Snow-Rain \\
20 & 3.6 & -5.8 & 21.2 & 07 & 300 & Drizzle-Rain \\
21 & 1.2 & -0.8 & 49.1 & 15 & 360 & Snow \\
22 & 1.4 & -0.6 & 13.1 & 15 & 330 & Snow \\
23 & 2.8 & -0.8 & 32.2 & 14 & 300 & Snow-Hail \\
24 & 3.2 & -2.0 & 7.3 & 10 & 330 & Snow \\
25 & 4.4 & -5.6 & 0.0 & 04 & 180 & Clear \\
26 & 6.2 & -6.0 & 0.0 & 05 & 230 & Clear \\
27 & 5.8 & -4.4 & 0.1 & 06 & 260 & Semi cloudy \\
\hline
\end{tabular}

coast. Therefore, it would be necessary to carry out research cruises particularly in span of the winter season when deep water formation is expected to occur (Froehlich et al., 1999).

Current study presents the results of the CTD-DO probe measurements in the southwestern part of the CS across one transect adjacent to the Anzali Port (AP), in early winter 2008. Probe profilings were exceeded down to $720 \mathrm{~m}$ in the Iranian waters which brought some insights to the deep water structure and winter convection in the study area. Also vertical structures of the physical characteristics and stratifications were investigated in mid and deep water of the southwestern part of the CS. Furthermore the gathered data sets revealed some new aspects of different water masses in the study area. The field survey was carried out while an unprecedented cold winter in the past 40 years occurred as reported by the local meteorological stations. Table 1 , demonstrates some meteorological parameters in the study area immediately prior and after to field survey. According to the statistics which were recorded in Anzali Synoptic Platform, south western part of the CS experienced sub zeros during that period which is not typical temperature for this region.

\section{Field data and CTD adaptation}

\subsection{Study area}

The study area is located in the southwestern part of the CS adjacent to the AP (Fig. 1). The depth decreases gently from the coast to approx. $-50 \mathrm{~m}$ near the shelf break in almost $10 \mathrm{~km}$, after that it sharply decreases to $-800 \mathrm{~m}$ in $25 \mathrm{~km}$. According to the bathymetric features, the continental shelf spreads from the coast up to about $10 \mathrm{~km}$ seaward with mild declination, which ensues by a drastic depression (the continental break) extends to $20 \mathrm{~km}$ seaward and hits its lowest point at $600 \mathrm{~m}$. The continental rise commences from this

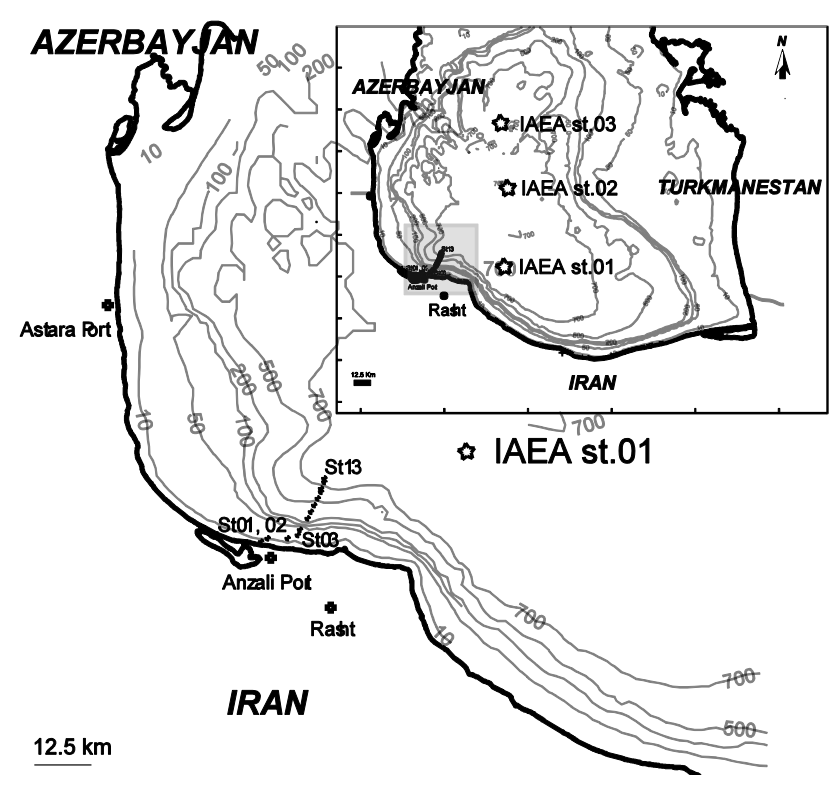

Fig. 1. The study area and CTD stations in the south western waters of the Caspian Sea.

point and goes down with a relatively mild slope with respect to the continental break toward the abyssal plain. The Anzali Lagoon (AL) is located at the southwestern corner of the CS beside of the delta of the Sepidrood (Sefidrood) River. This river supplies about $50 \%$ of riverine freshwater inflow and approximately $90 \%$ of sediment discharge to the CS along the Iranian coast where the Iranian side share in freshwater inflow does not exceed more than $5 \%$ of total riverine freshwater input to the CS (Lahijani et al., 2008). Moreover the area benefits from considerable precipitation and does not have a dry season (Sharifi, 2006). Therefore, to some extent the freshwater budgets of the AL and the Sepidrood River are considerable in the region. Due to the freshwater budget the 
southern part of the CS has the maximum basinwide salinity (Millero et al., 2008) that increases toward the south and the east. The southern coast of the CS has a subtropical climate characterized by warm summers and mild winters (Kosarev and Yablonskaya, 1994). The air temperature is maximum in August and minimum in January (Kaplin, 1995; Kosarev and Yablonskaya, 1994). While the sea surface temperature attains its annual minimum of about $7{ }^{\circ} \mathrm{C}$ in February, in span of warmer phase the maximum surface temperature exceeds $27^{\circ} \mathrm{C}$ in the southern basin (Kaplin, 1995; Tuzhilkin and Kosarev, 2005). The temperature in the deep water of the CS is well below the annual mean temperature of the seasonal mixed layer and in the southern basin it is even below the annual minimum of the monthly surface temperature (Tuzhilkin and Kosarev, 2005).

\subsection{Field measurements}

On 22 January 2008, a total of thirteen CTD casts were made along a transect extending from the mouth of the AL towards the offshore region (Fig. 1). The stations were selected based on the bathymetric contours in approximately $3 \mathrm{~km}$ intervals to cover some specific depths along the study area. The first station located at latitude $37^{\circ} 29.185 \mathrm{~N}$ and longitude $49^{\circ} 27.959 \mathrm{E}$ off $\mathrm{AP}$ and the last one located at latitude $37^{\circ} 44.121 \mathrm{~N}$ and longitude $49^{\circ} 40.470 \mathrm{E}$. According to the bathymetric features, the profiled stations well covered the deepest parts of the Iranian waters and could be representative for deep water characteristics in this region.

Measurements of in situ physical parameters such as pressure, temperature, conductivity and dissolved oxygen were made using an Ocean Seven 316 CTD probe produced by Idronaut Italy. The probe passed pre-calibrations and lab procedures former to survey in order to achieve precise estimates of conductivity $\left( \pm 0.003 \mathrm{~ms} \mathrm{~cm}^{-1}\right)$, temperature $\left(0.003{ }^{\circ} \mathrm{C}\right)$, and pressure $(0.05 \%$ full scale). Dissolved oxygen measurements were made using a routinely calibrated polarographic oxygen sensor which is insensitive to nitrogen, nitrous oxide, carbon dioxide and other gases. In addition to aforementioned parameters, the probe was equipped with ancillary sensors such as Chlorophyll- $a, \mathrm{pH}$ and turbidity. The CTD speed into the water was maintained nearly constant at $1 \mathrm{~ms}^{-1}$ during the casts (Pinot et al., 1997). The data quality was ensured through careful data inspection, de-spiking and checking for duplicate records.

\subsection{Method}

In oceanographic studies the calculation of salinity and density from CTD measurements is usually based on the empirical equations given by UNESCO (1981a, b). In view of the fact that empirical relations are valid only for water which has the ionic composition of standard sea water, they cannot be applied directly to the CS water. Millero and Chetirkin (1980) have conducted laboratory experiments to provide an empirical equation of state for the CS water. Unfortunately, the relation was valid only at surface pressure in specific temperature range. Peeters et al. (2000), using basinwide water samples collected in the CS (IAEA, 1996) modified the experimental equations for salinity and density based on the ionic composition of the CS. Their results showed that the salinity computed from CTD data by using the standard processes of UNESCO (1981b) is systematically less than the salinity obtained from the chemical methods, and the best agreement between the instrumental UNESCO formula and the chemical titration method in the CS can be obtained by applying a modification factor of 1.1017 as follows

$\mathrm{Sal}_{\text {Casp }}=1.1017 \mathrm{Sal}_{\text {sea }}$

where 1.1017 is the correction factor, $\mathrm{Sal}_{\text {sea }}$ is computed salinity using UNESCO equations, and $\mathrm{Sal}_{\text {Casp }}$ is the corrected salinity for the CS water. The Eq. (1) is independent of pressure, temperature and salinity ranges and could be used for different conditions and depths.

The international equation of state, i.e. density as function of temperature, salinity and pressure, for standard sea water $\rho_{\text {sea }}$ (UNESCO, 1981a) can be applicable to the CS by using Peeters et al. (2000) approach as follows:

$\rho$ solution $=\rho_{\text {sea }}(T P)+f(T P)\left(\rho_{\text {sea }}(T S P)-\rho_{\text {sea }}(T P)\right)$

where in Eq. (2), $\rho_{\text {sea }}(T P)$ is the density of the water computed from UNESCO formula using in situ temperature and pressure, in freshwater, $\rho_{\text {sea }}(T, 0, P)$ is the density of water from UNESCO formula using in situ temperature, pressure and salinity and $f(T, P)$ is the correction factor ( $f=1.0834$ ), that was assumed to be constant in all computations. In the present study we computed salinity and density of the CS based on the equations presented by Peeters et al. (2000) which seemingly are applicable for whole basin concerning the basin wide supporting data in derivation.

\section{Result and discussion}

\subsection{Physical properties structures}

Figure 2 shows the physical properties structure along the transect perpendicular to the coastline up to about $32 \mathrm{~km}$ seaward. The depth in this transect started from $5 \mathrm{~m}$ at the first station and increases to $720 \mathrm{~m}$ at the last one. The vertical structure of salinity in the study area in early winter 2008 is presented in Fig. 2b. Outside of the continental shelf zone, the variation of the salinity is small and varies $\sim 0.2 \%$ o from surface to $300 \mathrm{~m}$, i.e. at surface layer salinity is $12.242 \%$ ond reaches $12.425 \%$ at almost $300 \mathrm{~m}$ and maintains approximately the same value to the seabed. The measured salinity values are in well agreement with former observations (Kaplin, 1995; Kosarev and Yablonskaya, 1994; Tuzhilkin and Kosarev, 2005). The radical transformation of the vertical salinity structure of the CS waters is the most 


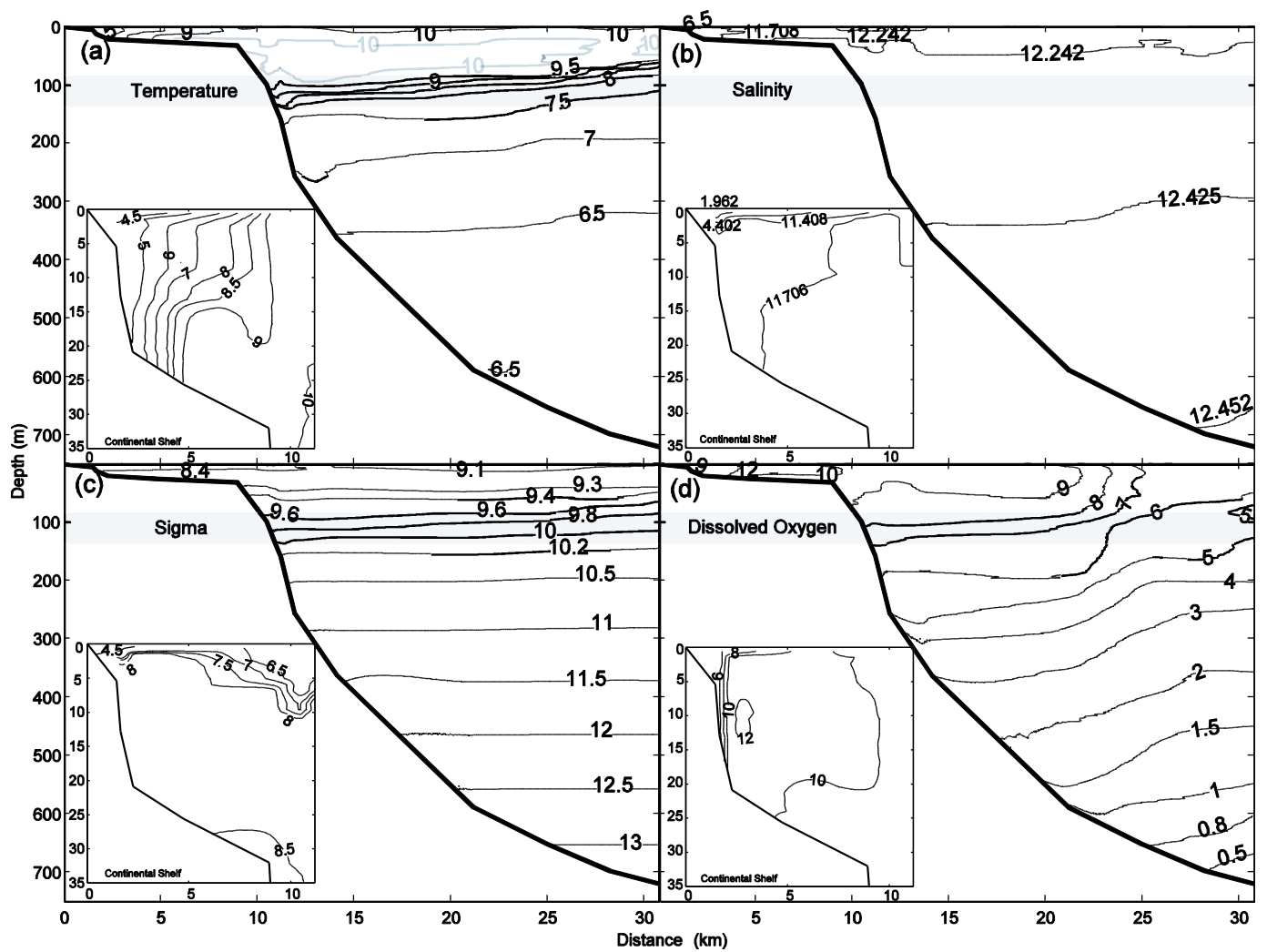

Fig. 2. Physical properties structures in cross-shore transect in the southwestern part of the CS; off AP in early winter 2008, the left side of the graphs is coast and right side is seaward (northward); vertical temperature structure (a), vertical salinity structure (b), vertical density distribution (c), and dissolved oxygen concentrations (d). The vertical structure of each physical property on the continental shelf area is presented in the inside panels.

prominent event in the hydrological condition of this water body. By plunging the water salinity over the whole Caspian basin in the late 1970 s, a stable vertical salinity stratification was formed (Tuzhilkin and Kosarev, 2005). This stratification was most pronounced in the early 1990s and in that period, vertical differences in salinity values made $0.5 \%$ in the southern part of the CS. However lately, a reverse trend has begun to manifest itself and leads again to quasi-homogeneous vertical distribution of the salinity values (Tuzhilkin and Kosarev, 2004). Although the southwestern part of the CS could be mentioned as quasi-homogenous in terms of salinity but concerning to the present vertical distribution, the structure could still be classified as the subarctic type, which has been observed from middle 1990s (Tuzhilkin et al., 2005). Horizontal variations of salinity over the continental shelf represent the influence and extend of freshwater inflow from the AL. Horizontal differences in salinity values over the continental shelf are noticeable and vary in range of $\sim 2.0 \%$ o (Fig. 2b the inside panel) to $11.708 \%$ o. The plume of AL inflow under the effect of negative buoyancy goes to the level where the density of the plume and surrounding waters are equal. The external freshwater budget, mainly river runoff, is the evident cause of the evolution in the salinity structure of the study area.
Relatively shallow waters of the continental shelf which are extended to about $10 \mathrm{~km}$ from the coast are clearly under the influence of the AL inflow and winter cooling (Fig. 2a). Therefore winter convection penetrates almost down to the seabed and vertical mixing is evident in this region. Contrary to the strong summer thermocline in southern part of the CS that partially maintains itself in continental shelf zone (Zaker et al., 2007), the water body in the cold phase over the continental shelf is completely ventilated and located in the surface mixed layer. However the inflow of the AL is traceable over the whole continental shelf zone. The cold water inflow of the $\mathrm{AL}$ (approx. $1^{\circ} \mathrm{C}$, Fig. 2a the inside panel), warms up to $9^{\circ} \mathrm{C}$ by dilation procedures with ambient waters as expands seaward. Owing to the cold phase erosion, the seasonal thermocline inevitably sinks down to the deeper layers and is located between 80 to $140 \mathrm{~m}$ depth with $2^{\circ} \mathrm{C}$ difference. According to Bruevich (1973), the maximum depth of winter convection in deep part of south CS and near the Iranian coastal zone varies between $80-100 \mathrm{~m}$ and $40-60 \mathrm{~m}$ respectively, which apparently is exceeded during this specific winter. Below the thermocline layer the temperature decreases gradually to $6.5^{\circ} \mathrm{C}$ in approx. $300 \mathrm{~m}$ and maintains the same quantity toward the seabed. Therefore based on the isotherm patterns, the seasonal mixing does not penetrate further than 

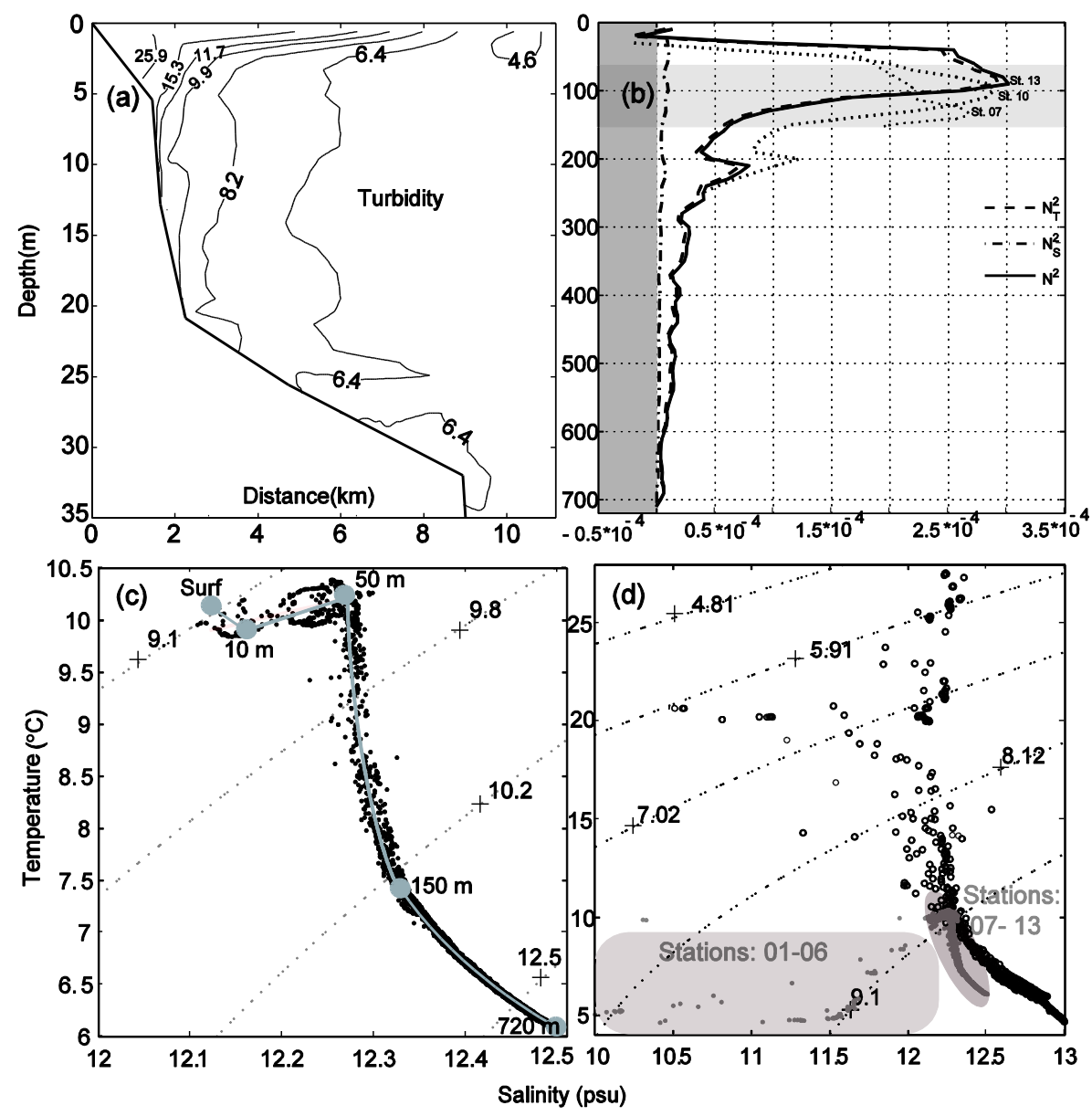

Fig. 3. Vertical Turbidity structure over the continental shelf, representing the high turbid inflow of AL. The turbidity unit is considered as NTU (a), Brunt Väisälä frequency $N^{2}$, which is a measure of the local stability of the water column, at the deepest station (solid line) and two shallower stations (dotted line) in the study area. $N^{2}$ is the sum of the contribution to stability by the temperature gradient $N_{\mathrm{T}}^{2}$ and by salinity gradient $N_{\mathrm{S}}^{2}$ (b), T-S diagrams for outside the continental shelf (stations No. 07-13) in the southern western part of the CS in early winter 2008 (c), $T$-S plot of stations 01 to 03 of IAEA cruise 1996 which located in the south CS, in comparison with present study data (d).

$300 \mathrm{~m}$ in the study area, and deep waters (lower than $300 \mathrm{~m}$ ) behave almost impermeable against seasonal variances.

Heating and cooling of the water column during warm and cold phases are account for partial or complete turnover in lakes which often are supported by wind forcing (Hohmann et al., 1997). Inclination of the thermocline layer towards the shelf break (Fig. 2a gray band) could support the hypothesis that turbulent diffusion cannot be the only mixing process. Hence, the processes causing oxygen-rich water to advect as density plumes from shallower parts down to the greater depths of the study area could be driven by horizontal temperature differences. Most probably the continental shelf water well cooled by AL inflow extreme winter and horizontal mixing of such water with moderately warmer shelf break water creates intense thermal bars which can produce waters dense enough to sink. As the salinity within the inflow is lower than that of the ambient water therefore, the salinity differences most likely do not play a significant role in driving the possible mixing process. Although the inflow of the AL is considerably fresher than the CS water, which could prevent such a mixture from sinking, but convection could also be generated by an increased load of suspended particles (Fig. 3a), in the water as is the case for riverine inflows (Peeters et al., 2000; Vollmer et al., 2002).

The vertical structure and evolution of the density field is a function of both salinity and temperature; the function depends on the seasonal variability of these parameters. Apparent density is calculated using the adopted equation of the state for the CS water (Fig. 2c). Accordingly, the density in the upper layer slowly increases (from 1009.1 to $1009.6 \mathrm{~kg} \mathrm{~m}^{-3}$ ) at $80 \mathrm{~m}$ surface layer. A quasi-homogeneous layer about $80 \mathrm{~m}$ thick is formed in the density structure and a broad seasonal pycnocline is formed under this layer which is extended to $150 \mathrm{~m}$ depth resemblance to thermocline layer. Contrary to the density field in the warming-up phase (Zaker et al., 2007), in cooling phase, the temperature drop results 
an increase in the upper layer density and the thickness of the mixed quasi-homogeneous layer. Underneath the thermocline layer the density increases gently from 1010.5 to $1013.0 \mathrm{~kg} \mathrm{~m}^{-3}$ in the seabed. Horizontal variations of the density field in the continental shelf area could be attributed to the intrusion of the $\mathrm{AL}$ inflow which adds riverine water into the sea (Fig. 2c the inside panel).

The AL low dissolved oxygen inflow water (approx. $5.0 \mathrm{mg}^{-1}$ ) is ventilated and mixed over the continental shelf area. The dissolved oxygen concentrations reach their highest value of $12.0 \mathrm{mg} \mathrm{l}^{-1}$ on the middle of the continental shelf in early winter 2008 (Fig. $2 d$ the inside panel). The well ventilated and highly oxygenated water is extended through the surface mixed layer over the continental shelf and shelf break (approx. $20 \mathrm{~km}$ from coastline). The oxygen concentrations in the upper $100 \mathrm{~m}$ mixed layer, owing to high ventilation and low temperature, is high and mainly ranged between 10.0 to $7.0 \mathrm{mg} \mathrm{l}^{-1}$. There is a considerable depression $(+100 \mathrm{~m})$ in the dissolved oxygen isoclines over the continental break and continental rise. The declination of the oxygen contours over the shelf break could be qualified by winter convection and sinking upper waters which pushing down the oxygen isoclines (Fig. 2d). Tuzhilkin et al. (2005) reported the oxygen concentrations of the south CS about 6.5$7.5 \mathrm{mg}^{-1}$ in the $100 \mathrm{~m}$ surface layer and 4.0 to $2.5 \mathrm{mg} \mathrm{l}^{-1}$ as the mean annual absolute content of dissolved oxygen in the $200-600 \mathrm{~m}$ layers. Therefore finding the surface layers oxygen $\left(6.0 \mathrm{mgl}^{-1}\right)$ in $200 \mathrm{~m}$ is indicating that fully ventilated continental shelf waters spread over the continental shelf break and lean the oxygen isoclines under the influence of the winter convection. The tilt of oxygen isoclines in lower layers shows the penetration of high oxygenated waters from the upper layer; i.e. above $200 \mathrm{~m}$. Because biodegradation leads to oxygen depletion, the intrusions are most likely recent features. Although a major convection event has not occurred such as what happened in 1976, which caused oxygen concentrations to reach around $9.0 \mathrm{mg} \mathrm{l}^{-1}$ in the deep waters of the central basin (Kosarev and Yablonskaya, 1994), but it could be mentioned that in the early winter 2008, a considerable winter mixing triggered at least in the lateral water boundary of the southwestern part of the CS; which could be traceable down to $500 \mathrm{~m}$ depth in terms of dissolved oxygen. Lower than $600 \mathrm{~m}$ depth, dissolved oxygen concentrations are strongly under-saturated $\left(\mathrm{O}_{2} \mathrm{sat}=4.2 \%\right)$ and less than $0.5 \mathrm{mg}^{-1}$ (approx. $650 \mathrm{~m}$ ) due to oxygen consumption. According to Tuzhilkin et al. (2005) reports on the near-bottom oxygen concentration averaged $\left(1.5 \mathrm{mg} \mathrm{l}^{-1}\right)$ over 1958-2000, the present concentration is reduced almost to one third. This decrease is caused by the weakening of the winter time convective ventilation in the deep waters and strengthening of the abyssal destruction processes.

\subsection{Stability and water masses}

In terms of the measured temperature and salinity, the Brunt Väisälä frequency $N^{2}$ which is representative for the local stability across the water column (Gill, 1982; Sverdrup et al., 1942) are calculated for deeper stations (Fig. 3b). All data were averaged in $10 \mathrm{~m}$ depth bins (Vollmer et al., 2002) and smoothed out utilizing the linear least-squares method. In agreement with the earlier calculations which have done by Peeters et al. (2000) for other parts of the CS, the stability values are positive in the study area as well. The contribution to the stability by the temperature gradient is significantly larger than that by the salinity gradient along the water column.

In order to index water structures and to separate various water types and masses in the study area, $T-S$ and $T-O$ diagrams are presented in Figs. 3c,d and 5. As demonstrated in the Fig. 3c, three segments in $T-S$ diagram of the deep stations (stations 07 to 13) are separable. Based on the classic definition of water mass (Mamayev, 1975), two different water masses could be identified at the surface layer down to $50 \mathrm{~m}$ depth and the deep water mass from $150 \mathrm{~m}$ down to the seabed. The layer between $50 \mathrm{~m}$ and $150 \mathrm{~m}$ could be considered as specific part of the $T$-S diagram which shows transitional properties. Therefore it could be concluded there is a rather shallow surface layer above $50 \mathrm{~m}$, a water mass WM1 at $50 \mathrm{~m}$, another water mass WM2 at depth $(720 \mathrm{~m}$ and deeper), and a water mass somewhere near $T=7.2^{\circ} \mathrm{C}$ and 12.29 salinity. The TS-values observed at $150 \mathrm{~m}$ would then be the result of mixing between WM1 and WM2. In surface layer owing to freshwater intrusion the salinity is dominant factor and has vertical gradient whereas the layer is almost constant in terms of temperature. In the deep layer (lower than $150 \mathrm{~m}$ ), the $T-S$ curve inclination is approximately $45^{\circ}$ which confirm equal contribution of temperature and salinity in the density field stratification. Additionally in transition part while temperature has considerable vertical gradient, in terms of salinity it could be considered as vertically quasihomogeneous.

In Fig. 3d, T-S diagram for the stations $01-13$ is plotted against stations (01-03) of the IAEA cruise (in the southern basin of the CS) in winter 1996. During very cold wintertime vertical rotation is effective in the deep water formation (Kosarev, 1962; Terziev et al., 1992; Terziev, 1992). The surface temperature in the southern basin attains its annual minimum of about $7^{\circ} \mathrm{C}$, while the basin-mean surface temperature is about $9^{\circ} \mathrm{C}$ (Kosarev and Tuzhylkin, 1995). According to Fig. $3 \mathrm{~d}$ the temperature of the lateral waters is well below the annual minimum and might be capable to sink to deeper layers, the increase in density due to seasonal cooling in deeper stations is not sufficient to cause major convection.

In view of the fact that distribution of salinity is semihomogeneous in vertical outline in the CS, T-O diagram is more illustrative to identify water masses in this water body (Terziev et al., 1992). According the Fig. 4 dissolved 


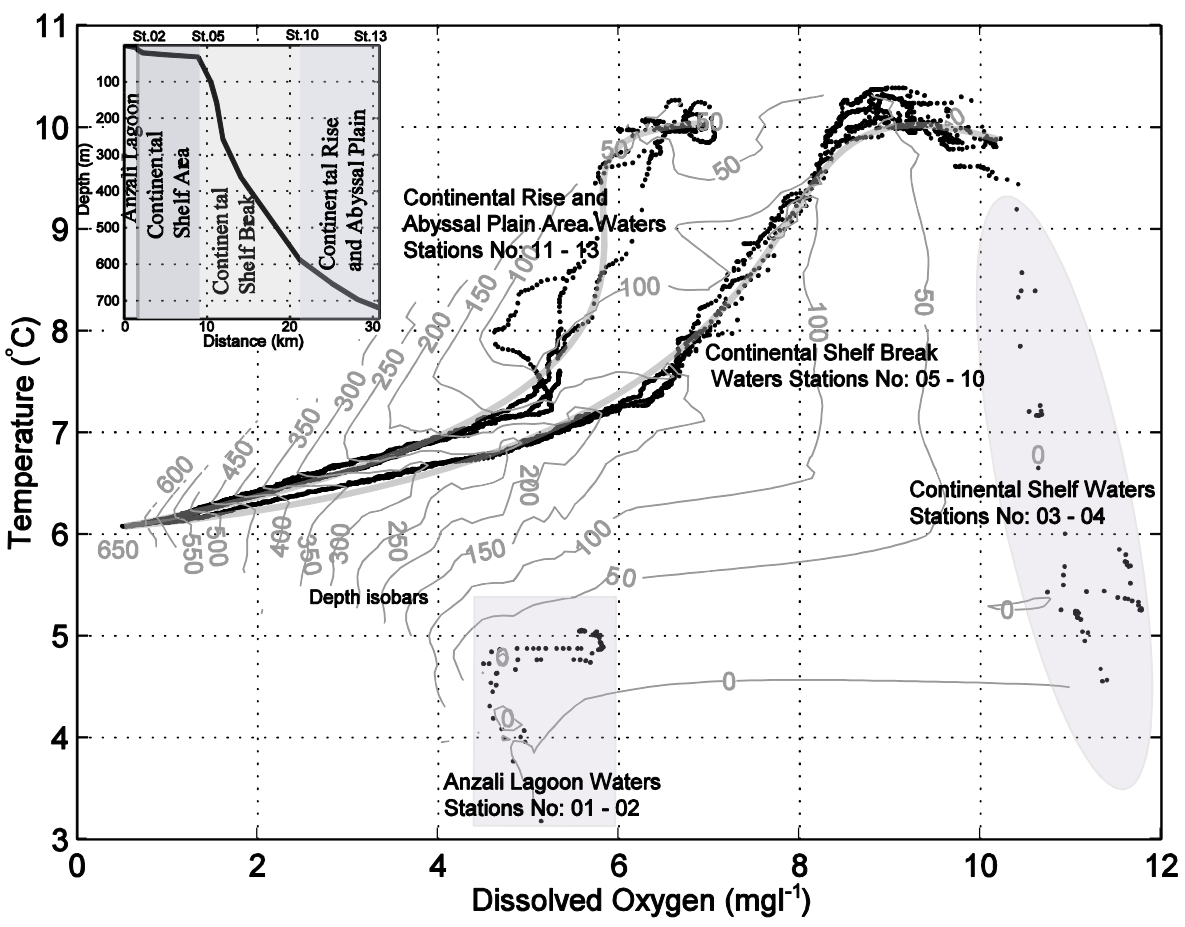

Fig. 4. T- $O$ diagram along the transect perpendicular to the coastline in the study area in early winter 2008; the top left panel demonstrates bathymetric features of the study area, the bottom shaded areas left to right represent dissolved oxygen concentrations versus temperature in stations 01-02 AL (inflow) and stations 03-04 over the continental shelf respectively.

oxygen ranges between $4.5-6.0 \mathrm{mg}^{-1}$ in stations 01 and 02 which indicating cold and low dissolved oxygen inflow waters of the AL. Additionally over the continental shelf area owing to ventilation processes, dissolved oxygen concentrations increase and reach to the maximum amount near to $12.0 \mathrm{mg} \mathrm{l}^{-1}$. The time temperature increases gradually from 5 to $10^{\circ} \mathrm{C}$ over the continental shel; therefore there are two distinguishable waters, which are completely detached from the deeper stations. In terms of oxygen concentrations, the upper layer in the continental shelf area is under the influence of fresh and cold water inflow of the AL, and lower layer adjoined with the main southwestern Caspian waters.

Among the deeper stations (from station 05 to 13), T-O diagram illustrates two water masses: surface and deep waters. The surface layer extends from the surface to $50 \mathrm{~m}$. In these stations the maximum dissolve oxygen concentrations were observed in the surface layer about 9.0-10.4 and $6.0-7.0 \mathrm{mg} \mathrm{l}^{-1}$ over the shelf break (stations 05-10) and continental shelf rise (stations 11-13) respectively, where the temperature shows its maximum value (on average $10^{\circ} \mathrm{C}$ ). In the middle layer (from 50 to $150 \mathrm{~m}$ ) the shelf break waters are warmer and more oxygenated than the seaward waters. Below the middle layer, the dissolved oxygen decreases drastically from almost $6.0 \mathrm{mg}^{-1}$ to $0.5 \mathrm{mg}^{-1}$ which forms the deep waters. According Terziev et al. (1992) two water masse; surface (surface to $50 \mathrm{~m}$ ) and deep (from $50 \mathrm{~m}$ to seabed) were hardly separable based on $T-O$ diagram during the cold phase in the south CS. However current results show two different water masses in terms of temperature-oxygen are distinguishable which are separated by a transition layer with $100 \mathrm{~m}$ thickness. The separation of $T-O$ graphs of the shelf break and seaward waters could be attributed to lateral winter mixing in the study area which causes penetrating high oxygenated waters to lower depths over the shelf break. Additionally the separation can lead us to trace the lateral winter mixing down to approx. $500 \mathrm{~m}$ in the shelf break zone.

\section{Conclusion remarks}

Physical (temperature, salinity and density) structures and dissolved oxygen concentrations and their variations over the southwestern part of the CS off AL, Iran, were presented and discussed using field survey data collected on 22 January 2008. Different water masses in study area were discussed as well. The variability of the vertical thermohaline structure is caused by both local and external factors (heat and moisture fluxes through the sea surface, the momentum and relative vorticity of the wind), and the characteristics of water circulation. Based on the recorded data it is concluded that:

- The continental shelf area is located in a well mixed layer and the fresh and cold water inflow of AL is traceable over the shelf break. Outside the continental shelf, 
the thickness of the well mixed layer differs from 120 to $80 \mathrm{~m}$ as progressing seaward, therefore a deepening of the thermocline layer is happened in larger scale than former estimations in southern waters of the CS. According to the isotherm patterns, the seasonal mixing does not penetrate further than $300 \mathrm{~m}$ in the deeper stations (continental rise and abyssal plain areas), therefore it seems these waters (lower than $300 \mathrm{~m}$ ) are not affected by seasonal variation.

- Although the salinity shows quasi-homogeneous pattern in the pycnocline between $50 \mathrm{~m}$ to $150 \mathrm{~m}$ depth, there are vertical salinity gradient in both surface and deep layers. Salinity is the main factor of the significant density stratification (static stability) at the surface. But concerning the slope of the $T-S$ curve in lower than $150 \mathrm{~m}\left(\sim 45^{\circ}\right)$, salinity plays the equal role as temperature in the density stratification. Therefore the salinity structure and the density field are comparable with subarctic zones at the World Oceans (WOA05, 2005).

- Based on the dissolved oxygen pattern, it seems that the fully ventilated continental shelf waters spread to the continental shelf break area. The tilt of the oxygen isoclines in the lower layers shows the penetration of high oxygenated waters from the upper layers which seem to be recent features. Although the deep waters in the seaward stations behave as impermeable against seasonal variations, but in terms of the dissolved oxygen concentrations it could be mentioned that a mixing triggered at least in the lateral waters of the study area.

- It could be mentioned that the stability is positive in most of the regions in the study area and mostly affected by temperature gradient than salinity gradient.

- According to the T-O diagram the coastal water that is fairly located in the AL inflow and the continental shelf waters behave as detach masses. A new frame of the water masses, particularly in aspect of temperature-oxygen structure is demonstrated within the deeper stations of the study area. Despite to previous studies which were drawing two (surface and deep) water masses that were not completely separable, present study confirms two sharply distinguishable water masses.

Acknowledgements. This study has been supported by Iranian National Center for Oceanography (INCO) in the framework of Physical Oceanography Cruise of the Southern Caspian Sea (Project No. 386-02-17). We acknowledge F. Peeters for his constructive comments and suggestions regarding the stability of the Caspian Sea and Suzanne Leroy for editing and standardizing the English language of manuscript.

Edited by: E. J. M. Delhez

\section{References}

Bruevich, S. V.: Hydrochemistry of Middle and South Caspian Sea, USSR Academy of Sciences, Moscow, 1973.

Froehlich, K., Rozanski, K., Povinec, P., Oregioni, B., and Gastaud, J.: Isotope studies in the Caspian Sea, Sci. Total Environ., 237/238, 419-427, 1999.

Gill, A. E.: Atmosphere-Ocean Daynamics, Academic Press, San Diego, 1982.

Hohmann, R., Kipfer, R., Peeters, F., Piepke, G., and Imboden, D. M.: Processes of deep-water renewal in Lake Baikal, Limnol. Oceanogr., 42, 841-855, 1997.

IAEA: Research/Training on the Caspian Sea, Data Report 1995, International Atomic Energy Agency, Wien, 1996.

I. R. of Meteorological Org.: http://www.irimo.ir/farsi/marinehava/ northseachoose.asp/ last access: 10 February 2010, 2008.

Kaplin, P.: The Caspian: Its past, present and future, in: Enclosed seas and large lakes of eastern Europe and middle Asia, edited by: Mandych, A. F., SPB, The Hague, 1995.

Kosarev, A. N.: Water Masses of the Caspian Sea, Georgrafia, 45$51,1962$.

Kosarev, A. N. and Tuzhylkin, V. C.: Climatic Thermohaline Fields of the Caspian Sea, Moscow, 1995.

Kosarev, A. N. and Yablonskaya, E. A.: The Caspian Sea, SPB Academic Publishing, 1994.

Lahijani, H. A. K., Tavakoli, V., and Amini, A. H.: South Caspian river mouth configuration under human impact and sea level fluctuations, Environ. Sci., 5, 65-86, 2008

Lebedev, S. A. and Kostianoy, A. G.: Satellite altimetry of the Caspian Sea, European Space Agency, Special Publication, SP614, 113-120, 2006.

Mamayev, O. I.: Temperature-salinity analysis of World Ocean waters, Elsevier Scientific Publishing Company, Amsterdam, The Netherlands, 1975.

Millero, F. J. and Chetirkin, P. V.: The density of Caspian Sea waters, Deep-Sea Res., 27, 265-271, 1980.

Millero, F. J., Mirzaliyev, A., Safarov, J., Huang, F., Chanson, M., Shahverdiyev, A., and Hassel, E.: The Equation of State for Caspian Sea Waters, Aquat. Geochem., 14, 289-299, 2008.

Peeters, F., Kipfer, R., Achermann, D., Hofer, M., AeschbachHertig, M., Beyerle, U., Imboden, D. M., Rozanski, K., and Fröhlich, K.: Analysis of deep-water exchange in the Caspian Sea based on environmental tracers, Deep-Sea Res. Pt. I, 47, 621-654, 2000.

Pinot, J. M., Velez, P., Tintore, J., and Lopez-Jurado, J. L.: The thermal-lag effect in SBE-25 CTDs: Importance of correcting data collected in the Mediterranean summer thermocline, Sci. Mar., 61, 221-225, 1997.

Rodionov, S. N.: Global and regional climate interaction : the Caspian Sea experience, Kluwer Academic Publishers, Dordrecht, The Netherlands, 1994.

Safarov, J. T., Mirzaliyev, A. A., Shahverdiyev, A. N., and Hassel, E. P.: $(p, \rho, T)$ Properties of the Caspian Seawater, ICPWS XV, Berlin, 2008.

Sharifi, M.: The Pattern of Caspian Sea Water Penetration Into Anzali Wetland: Introduction of a Salt Wedge, Casp. J. Environ. Sci., 4, 77-81, 2006.

Sverdrup, H. U., Johanson, M. W., and Fleming, R. H.: The Oceans: Their Physics, Chemistry, and General Biology, Prentice-Hall, Inc, Englwood Clifs, New Jersy, 1942. 
Terziev, F. S., Kosarev, A. N., and Kerimov, A. A.: The Seas of the USSR, Hydrometeorology and Hydrochemistry of the Seas, Vol. VI: The Caspian Sea, Issue 1: Hydrometeorological Conditions, Gidrometeoizdat, St. Petersburg, 1992.

Terziev, S. F.: Hydrometeorology and Hydrochemistry of Seas, The Caspian sea, Hydrometeorologycal Conditions, Gidrometeoizdat, Leningrad, 1992.

Tuzhilkin, V. S., Katunin, D. N., and Nalbandov, Y. R.: Natural chemistry of Caspian Sea waters, in: The Caspian Sea Environment, edited by: Kostianoy, A. G. and Kosarev, A. N., Springer, Berlin/Heidelberg, 83-108, 2005.

Tuzhilkin, V. S. and Kosarev, A. N.: Long-term variations in the vertical thermohaline structure in deep-water zones of the Caspian Sea, J. Water Resour., 31, 376-383, 2004.

Tuzhilkin, V. S. and Kosarev, A. N.: Thermohaline structure and general circulation of the Caspian Sea waters, in: The Caspian Sea Environment, edited by: Kostianoy, A. G. and Kosarev, A. N., Springer, Berlin/Heidelberg, 33-57, 2005.
UNESCO, ICES, SCOR, IAPSO: Background papers and supporting data on the international equation of state of seawater 1980 , Unesco technical papers in marine science, Nr. 38, UNESCO, 1981a.

UNESCO, ICES, SCOR, IAPSO: Background papers and supporting data on the practical salinity scale 1978, Unesco technical papers in marine science, Nr. 37, UNESCO, 1981 b.

Vollmer, M. K., Welss, R. F., Williams, R. T., Falkner, K. K., Qiu, X., Ralph, E. A., and Romanovsky, V. V.: Physical and chemical properties of the waters of saline and their importance for deep-water renewal: Lake Issyk-Kul, Kyrgyzstan, Geochim. Cosmochim. Acta, 66, 4235-4246, 2002.

WOA05: http://www.nodc.noaa.gov/OC5/WOA05/pr_woa05.html/, last access: 15 February 2010, 2005.

Zaker, N. H., Ghaffari, P., and Jamshidi, S.: Physical Study of the Southern Coastal Waters of the Caspian Sea, off Babolsar, Mazandaran in Iran, J. Coast. Res., Special Issue, 50, 564-569, 2007. 